\title{
Casos Clínicos \\ Estatus Migrañoso con Pleocitosis Linfocítica: Reporte de un Caso
}

\author{
Status Migrainosus with Lymphocytic Pleocytosis: \\ A Case Report \\ Ernesto Bancalari-Benavides, $M D, M s C, P^{1,2}$, Aaron Rodriguez-Calienes ${ }^{3,4}$
}

Resumen

Un varón de 40 años, con antecedente de migraña, experimentó un episodio de cefalea occipital, tinitus y fotopsias. Fue tratado con analgésicos en la emergencia con alivio parcial durante 3 visitas consecutivas en la semana previa a la hospitalización. Al ingreso al piso de hospitalización, no se evidenciaron anormalidades en el examen físico general ni en el neurológico. Se realizó una punción lumbar (PL) la cual solo presentó 100 células mononucleares con niveles normales de proteína y glucosa. Estudios microbiológicos y virológicos en líquido cefalorraquídeo (LCR) y estudios de imágenes cerebrales no fueron contributorios. El dolor solo fue controlado luego de bloqueo nervioso trigeminal. Cinco días luego del ingreso y con el estatus migrañoso resuelto, una segunda PL se realizó donde no se reportaron anormalidades, así como la resolución de la pleocitosis mononuclear. El reconocimiento de la pleocitosis en el contexto de un episodio migrañoso agudo podría servir para evitar investigaciones innecesarias y el mal uso de recursos clínicos cuando no tienen indicación clínica.

Palabras clave: Migraña, líquido cefalorraquideo, cefalea.

Mensaje clave: El análisis del líquido cefalorraquídeo (LCR) es usualmente no investigado en el contexto de un ataque migrañoso agudo; sin embargo, el reconocimiento de los hallazgos en LCR, como la pleocitosis linfocítica, podría servir para evitar estudios innecesarios y el mal uso de recursos clínicos.

\section{Abstract}

A 40-year-old man, with a history of migraine, experienced a left occipital headache, tinnitus and photopsias. He was treated with analgesics at the emergency room with partial relief during 3 consecutive visits during the week prior to admission. At admission, general physical exam was normal as was the neurological examination. A lumbar puncture (LP) was performed, showing no blood cells but 100 mononuclear cells with normal protein and glucose levels. Cerebrospinal fluid (CSF) microbiological and virologic tests and brain imaging studies were not contributory. The pain was controlled after a trigeminal nerve block. Five days after admission and with the status migrainosus resolved, a second $L P$ was performed which was reported as normal with resolution of the pleocytosis. Recognition of transitory CSF pleocytosis in the context of an acute migraine episode could serve to avoid unnecessary investigations and misuse of clinical resources when not clinically indicated.

Keywords: Migraine, cerebrospinal fluid, headache.

Key message: Cerebrospinal fluid (CSF) analysis is not usually investigated in the context of an acute migraine attack; however, recognition of CSF findings, such as lymphocytic pleocytosis, could serve to avoid unnecessary investigations and misuse of clinical resources.

${ }^{1}$ Facultad de Medicina, Universidad Católica Santo Toribio de Mogrovejo, Chiclayo, Perú. ${ }^{2}$ Clínica Anglo Americana, Lima-Perú. ${ }^{3}$ Facultad de Medicina Humana, Universidad de San Martin de Porres, Lima, Perú. ${ }^{4}$ Grupo Estudiantil de Investigación en Neurociencias, Sociedad de Estudiantes de Medicina Humana de la Universidad de San Martin de Porres, Lima, Perú. 


\section{Introducción}

La migraña afecta a aproximadamente un billón de personas a nivel mundial, predominantemente a mujeres ${ }^{(1)}$. Anormalidades en el líquido cefalorraquídeo (LCR) son excepcionales y, cuando se evidencia, hacen dudoso el diagnóstico de migraña ${ }^{(2)}$. Por lo tanto, reportamos el caso de un paciente con estatus migrañoso asociado a pleocitosis transitoria en LCR. El paciente dio su consentimiento informado para la realización del presente reporte.

\section{Reporte del caso}

Un varón de 40 años, diestro, con antecedente de migraña experimentó un episodio de cefalea occipital izquierda pulsátil, tinitus y fotopsias. Fue tratado con analgésicos en la emergencia con alivio parcial durante tres visitas consecutivas en la semana previa a la hospitalización. Por este hecho y el empeoramiento de sus síntomas, fue hospitalizado en nuestra institución.

Luego de varios años con el diagnóstico de migraña, esta era la primera vez que el paciente había desarrollado un estatus migrañoso. Los síntomas persistieron durante el día y empeoraban con el movimiento. Al llegar, el paciente se encontraba afebril. El examen físico general fue normal, así como el examen neurológico: no se evidenció déficit motor, meningismo, diplopía, papiledema, o signos cerebelosos. El hemograma, glucosa, urea y electrolitos estaban en rangos normales. Se realizó una angiotomografía cerebral para descartar la presencia de hemorragia subaracnoidea secundaria a un aneurisma, como causa de la cefalea. El examen no evidenció anormalidades en el parénquima y solo demostró una arteria comunicante posterior hipoplásica.

Habiendo iniciado la cefalea más de tres días antes de la admisión, se realizó una punción lumbar(PL), la cual evidenció presión de apertura normal, ausencia de hematíes, pero presencia de 100 células mononucleares con niveles normales de proteína y glucosa. Por la sospecha de una meningitis viral (MV) se inició tratamiento con Aciclovir y analgesia parenteral para la cefalea.

Estudios microbiológicos y virológicos en el LCR fueron negativos. La resonancia magnética (RM) con gadolinio no mostró anormalidades, salvo un microadenoma pituitario. Consecuentemente, la posibilidad de una MV fue descartada y se detuvo el tratamiento con Aciclovir.

Considerando estos hallazgos, los síntomas fueron atribuidos a un estatus migrañoso. El dolor fue controlado luego de un bloqueo del nervio trigeminal con betametasona y xilocaína en solución al $2 \%$. Cinco días tras su ingreso y con el estatus migrañoso resuelto, se realizó una segunda PL que fue reportada como normal con resolución de la pleocitosis previa. El paciente fue dado de alta al día siguiente.

\section{Discusión}

Nuestro paciente presentó un estatus migrañoso con linfocitosis transitoria en LCR. A pesar de que existen diversas enfermedades que asemejan este síndrome, las investigaciones diagnósticas no evidenciaron ningún hallazgo significativo. El paciente tenía el antecedente de migraña hace varios años; sin embargo, este se trató del primer episodio de un estatus migrañoso y por lo tanto fue estudiado para descartar causas secundarias.

La asociación entre un síndrome migrañoso con pleocitosis en LCR fue inicialmente reportador por Bartleson et al. en siete pacientes sin antecedente de migraña ${ }^{(3)}$. Estos pacientes presentaron pleocitosis linfocítica con proteína y presión de apertura por encima de los valores normales. Además, cada paciente presentó un episodio de déficit neurológico y todos los casos fueron autolimitados y se desarrollaron en menos de tres meses. Luego, esta entidad adquirió el título de síndrome de cefalea, déficit neurológico y linfocitosis en LCR (HaNDL del inglés Headache, Neurological Deficit and cerebrospinal fluid Lymphocytosis) (4)

El síndrome HaNDL es una entidad rara y poco reconocida que puede relacionarse a un virus único o a una respuesta idiosincrática a una variedad de agentes virales ${ }^{(4)}$. A pesar que nuestro paciente compartía características del síndrome HaNDL, cefalea y pleocitosis en LCR, no presentó ningún déficit neurológico ni proteínas elevadas en LCR, que es una característica particular de este síndrome y componente de los criterios diagnósticos ${ }^{(5)}$.

En el contexto de un paciente con antecedente de migraña, una respuesta inflamatoria secundaria a un ataque migrañoso podría explicar los cambios asociados en el LCR. La inflamación neurogénica en la duramadre ha sido considerada un iniciador y conductor de los ataques migrañosos $^{(6)}$; sin embargo, esta evidencia proviene de estudios mayormente desarrollados en roedores ${ }^{(6)}$. Además, estos hallazgos no tienen respaldo de datos clínicos ${ }^{(7)}$ y los marcadores clásicos de inflamación del sistema nervioso central (SNC), como son cambios en la integridad de la barrera hematoencefálica, activación glial o infiltración leucocitaria, 
no se observan durante ataques migrañosos ${ }^{(8)}$. Por lo tanto, el rol de la inflamación del SNC en la iniciación de un ataque migrañoso ha sido cuestionado ${ }^{(8)}$.

Nos llama la atención este hallazgo en el LCR, dado que la PL no es parte de los estudios diagnósticos en el contexto de un paciente con migraña. Tal vez, podríamos encontrar más de estos casos si se realizara este procedimiento en pacientes con estatus migrañoso.
Dentro de lo que se conoce, la presencia de linfocitosis transitoria en el LCR es un hallazgo extremadamente raro durante un episodio agudo migrañoso y podría ser consecuencia de una respuesta inflamatoria. El reconocimiento de este hallazgo laboratorial podría servir para evitar investigaciones innecesarias y el mal uso de recursos clínicos cuando no tienen indicación.

\section{Referencias bibliográficas}

1. Stovner LJ, Nichols E, Steiner TJ, Abd-Allah F, Abdelalim A, Al-Raddadi RM, et al. Global, regional, and national burden of migraine and tension-type headache, 1990-2016: a systematic analysis for the Global Burden of Disease Study 2016. Lancet Neurol. 2018;17:954-976.

2. Kovacs K, Bors L, Tothfalusi L, Jelencsik I, Bozsik G, Kerenyi L, et al. Cerebrospinal Fluid (CSF) Investigations in Migraine. Cephalalgia. 1989;9:53-57.

3. Bartleson JD, Swanson JW, Whisnant JP. A migrainous syndrome with cerebrospinal fluid pleocytosis. Neurology. 1981;31:1257-1262.

4. Berg MJ, Williams LS. The transient syndrome of headache with neurologic deficits and cerebrospinal fluid lymphocytosis. Neurology. 1995;45:1648-1654.

5. Olesen J, Bes A, Kunkel R, Lance J, Nappi G, Pfaffenrath V, et al. Headache Classification Committee of the International Headache Society (IHS) The International Classification of Headache Disorders, 3rd edition. Cephalalgia 2018;38:1-211.

6. Pietrobon D, Moskowitz MA. Pathophysiology of migraine. Annu Rev Physiol. 2013;75:365-391.

7.Peroutka SJ. Neurogenic inflammation and migrane: Implications for therapeutic. Mol Interv. 2005;5:304-311

8. Edvinsson L, Haanes KA, Warfvinge K. Does inflammation have a role in migraine?. Nat Rev Neurol. 2019;15:483-490.

Contribución de autoría: EBB y ARC han participado en la concepción del artículo, recolección de datos, redacción, revisión crítica del manuscrito y aprobación de su versión final.

Conflicto de interés: Los autores no tienen conflicto de interés con la publicación de este trabajo.

Financiamiento: Autofinanciado.

Citar como: Bancalari-Benavides E., Rodriguez-Calienes A. Estatus Migrañoso con Pleocitosis Linfocítica. Reporte de un Caso. Diagnóstico(Lima). 2021;60(3):170-172. DOI: 10.33734 /diagnostico.v60i3.307

Correspondencia: Aaron Rodriguez Calienes. Avenida Ricardo Palma 547 San Joaquín Bellavista, Callao, Lima, Perú. Correo electrónico: aaron_rodriguez1@usmp.pe Teléfono: +51992096903

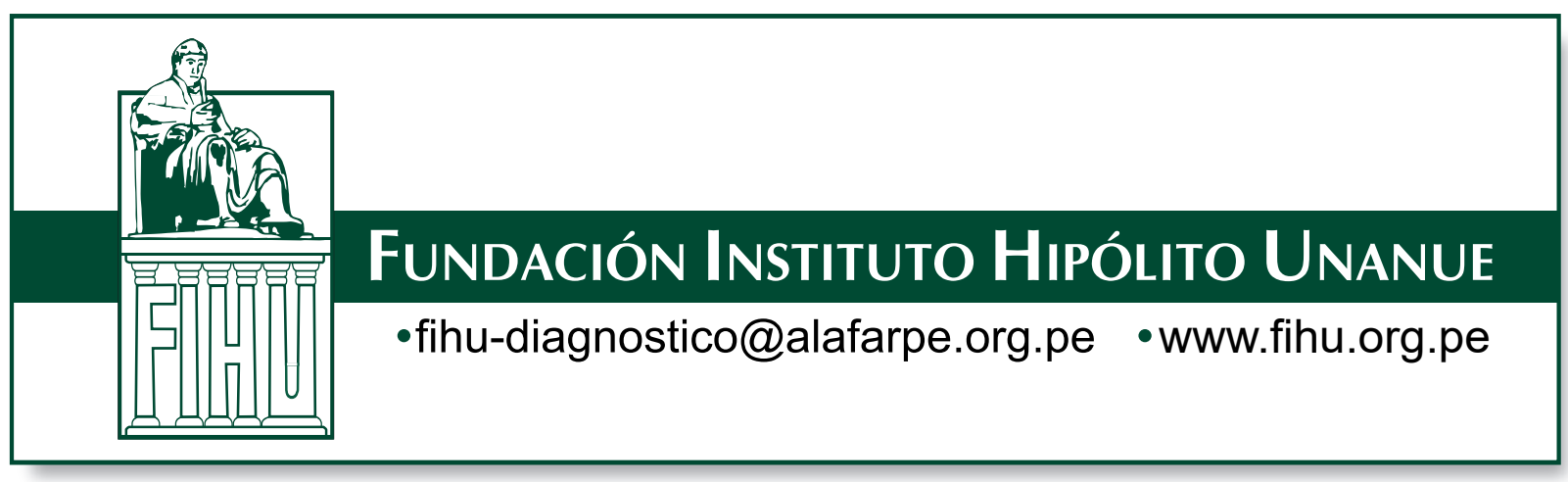

